\title{
DELEUZE SOBRE FOUCAULT: APRENDER PELA ESCUTA DO OUTRO
}

\section{DELEUZE SUR FOUCAULT: APPRENDRE EN ÉCOUTANT LES OUTRES}

\author{
David da Silva Pereira ${ }^{1}$ \\ Silvana Dias Cardoso Pereira ${ }^{2}$
}

\begin{abstract}
Resumo: Em out. 1985, Deleuze inicia um de seus últimos Cursos na Université de Paris 8 Vincennes Saint Denis. Ele elege, para tanto, as Formações Históricas em Michel Foucault, pouco mais de um ano da morte desse filósofo, seu contemporâneo. Na primeira sessão, do dia 22, Deleuze faz um sobrevoo inicial sobre as publicações foucaultianas (de 1961 a 1984). Ressalta a vedação que Foucault deixara para obras póstumas e, curiosamente, sinaliza a existência de um texto inacabado que seria publicado em 08. fev. 2018, na França, como A História da Sexualidade IV - Les Aveux de la Chair. Contudo, o que se pretende com esta reflexão é fixar a escuta na forma pela qual Gilles Deleuze resgata o legado foucaultiano para ressaltar dois períodos - 1961-1975 e 1975-1984.
\end{abstract}

Palavras-chave: Deleuze; Foucault; escuta do outro.

Resumé: En oct. 1985, Deleuze entame l'un de ces derniers cours à l'Université de Paris 8 Vincennes Saint Denis. Il choisit, pour cela, les Formations Historiques de Michel Foucault, un peu plus d'un an aprés la mort de ces philosophe contemporain. En première séance, le 22, Deleuze fait un pemier survol des publications de Foucault (de 1961 à 1984). Il souligne le sceau que Foucault a laissé pour des oeuvres posthumes et, fait intéressant, signale l'existance d'un texte inachavé qui serait publié le 8. février. 2018, en France, comme L'Histoire de la Sexualité IV - Les Aveux de la Chair. Mais cet réflexion a pour but de fixer l'écoute de la manière dont Gilles Deleuze sauve l'héritage foucaultien pour mettre en évidence deux périodes - 1961-1975 et 1975-1984.

Mots-clés: Deleuze; Foucault; à l'écoute de l'autre.

"faire confiance à l'auteur que vous étudiez" (Gilles Deleuze, 22. out. 1985, min. 23'30”)

\section{Presentation}

Gilles Deleuze foi contemporâneo de Paul-Michel Foucault. Nasceu em 1925, em Paris, ao contrário de Foucault que nasce um ano após, em Poitiers, e chegará em Paris apenas com vistas ao ingresso na École Normale Supérieure de la rue de l'Ulm, em 1945. Deleuze realiza um investimento concentrado na Filosofia na Université de Paris 1 - Sorbonne - e, fundamentalmente, em História da Filosofia. Foucault tem incursões pela Saúde, pela Clínica, pelos manicômios, assim como se encanta e reflete acerca do asilo, do confinamento dos loucos e do posterior "grande encarceramento" social. A Filosofia é, portanto, um caminho alternativo para Foucault que trilha um percurso que passa pela Psicologia, pela Psiquiatria e pela Psicanálise. No plano acadêmico, enquanto Deleuze ingressa como professor do Liceu vinculado à Université de Sorbonne para, depois, ingressar na docência da Educação Superior na Université de Lyon, Michel Foucault tem uma atuação estrangeira como uma espécie de

\footnotetext{
${ }^{1}$ UTFPR (GP OPP-UTFPR). E-mail: davidpereira@utfpr.edu.br.

${ }^{2}$ FE-Unicamp (GP ALLE-AULA FE-UNICAMP / OPP-UTFPR). E-mail: pereirasilvana319@ yahoo.com.br.
} 
adido cultural francês na Suécia, na Polônia e na Alemanha, atuação que o aproxima de um promotor da língua e da cultura francesa no exterior. Tais itinerários, entretanto, convergem para um encontro em Vincennes, na recém-criada Université de Paris 8 - Vincennes SaintDenis, no Curso e Departamento Acadêmicos de Filosofia entre 1968 e 1970. Mais tarde, seriam companheiros do Groupe d'Études sur les Prisons (GIP). Após a defesa de suas teses em Filosofia, Foucault após um percurso inicial acadêmico em Clemont-Ferrand e Deleuze em Lyon, o encontro profissional de Saint Denis não se prolonga no tempo em função da saída, pouco tempo depois, de Foucault para o Collège de France, em 1970. Deleuze, de outro modo, prossegue em Vincennes até o final de sua docência, em 1986, momento em que, como um de seus últimos atos acadêmico-filosóficos, promove cursos sobre Foucault, morto em 1984 em função dos comprometimentos da SIDA (Síndrome da Imunodeficiência Adquirida). Onze anos após, Deleuze insere um ponto final em sua trajetória ao saltar da janela de seu apartamento em Paris, já afastado da docência e debilitado. Deleuze e Foucault convivem o período de 1926 a 1984, segunda e terceira quartas partes do séc. $\mathrm{XX}^{3}$.

\section{Introduction}

Em 22 de outubro de 1985, Gilles Deleuze inicia um de seus últimos cursos na Université de Vincennes ${ }^{4}$. Ouvi-lo é um exercício inafastável. Sobretudo para quem se debruçou sobre a obra foucaultiana e os Cursos proferidos no Collége de France, entre 1978 e 19845. No biênio 1985-1987, em seus Cursos de História da Filosofia na Université de Paris 8 - Vincennes Saint Denis - ville ao norte de Paris e hoje integrada à capital francesa como parte da Île de France . $^{\circ}$ Ouvir a narrativa e as problematizações de Deleuze acerca das obras e das ideias articuladas em verdadeiros sistemas de pensamento por Michel Foucault é a oportunidade de retomar o percurso dos Cursos, agora a partir das primeiras obras, com vistas a desvelar um outro Foucault, um pensador retomado e restituído agora por Gilles Deleuze.

\footnotetext{
${ }^{3}$ Os textos e manifestações de Michel entre 1959 e 1984 foram reunidos em dois volumes com o título Dits et Écrits, sob a supervisão atenta de Daniel Defert, seu companheiro. Uma reedição revista foi publicada em Paris, em 2017.

4 Áudio e transcrição estão disponíveis em: http://www2.univ-paris8.fr/deleuze/article.php3?id article $=403 \& \_g a=2.143401404 .868570781 .1588366004-41936813.1588366004$. Acesso em: 1 maio 2020.

${ }^{5}$ Oportunidade concentrada entre jan. 2017 e fev. 2020, intervalo de concentração e de investigação detidas no Último Foucault. Esse esforço foi beneficiado por um período de afastamento integral da docência do autor deste artigo, entre ago. 2017 e jul. 2018, ano de acolhida pelo Prof. Dr. Silvio Donizetti de Oliveira Gallo do Departamento de Filosofia e de História da Educação da Unicamp, líder de um conjunto de esforços que envolve dezenas de investigadores em torno da Filosofia Francesa Contemporânea e suas contribuições para o pensar e o problematizar da vida e da educação. Entre nov. 2017 e jul. 2018, um período de estudos na França foi possibilitado por meio de uma bolsa CAPES de pós-doutoramento vinculada ao Projeto CAPES-COFECUB n. 844/2015, liderado pelo Prof. Silvio Gallo e que contou com parcerias importantes de investigadores franceses contemporâneos como os Profs. Alain Patrick Olivier (Université de Nantes) e Didier Moreau (Université de Paris 8 - Vincennes Saint Denis). Esse último atuou como cooperador de um processo de aprofundamento nos Cursos do Último Foucault (1978-1984), transição acentuada do binômico saber-poder para a ética. Após um ano sabático, Foucault teria o seu percurso intelectual final detido na Antiguidade Grega, por meio de duas ideias-chaves fundamentais - o souci de soi e a parresía. A coautora também se beneficiou dessa temporada e teve a oportunidade de realizar visitas técnicas com o autor no Collège de France, na Abbaye d'Ardenne e no Centre Michel Foucault. Por tais oportunidades, o agradecimento sincero ao promotor de tal oportunidade $-\mathrm{o}$ Prof. Silvio Gallo - aos mestres franceses e aos colegas brasileiros e estrangeiros que enriqueceram esse percurso. A oportunidade de ouvir Foucault, ter acesso aos manuscritos e efetuar uma aproximação contextual e presencial do lugar e das preocupações dessas reflexões foram oportunidades únicas.

${ }^{6}$ Sem dúvida, a presença de um terminal regional diante da Universidade de Paris 8, há uma caminhada de 20 minutos do cento de Saint Dennis, bem como a estação do metrô parisiense que tem adotou o nome dessa Instituição ampliaram $\mathrm{o}$ acesso a essa e à outra Universidade presente na vizinha ville de Vincennes, a Université de Paris 13.
} 
Trata-se de um exercício complexo e fundamental. Deleuze lê os textos, reconstrói o percurso do autor, destaca preocupações e sentidos das abordagens, enfatiza questões que estavam ou não anotadas nas margens das obras publicadas em português, mas que fazem emergir articulações outras. É honesto salientar que estes autores não se debruçaram sobre os Cursos de Deleuze antes que o anúncio do Encontro de 2019 fosse divulgado pelos investigadores e colegas dos Grupos PHALA e outros da Faculdade de Educação da Unicamp. Dessa forma, tem sido um exercício de muitas descobertas e de identificação de nuances e de problemáticas caras à Filosofia francesa contemporânea, em especial por alguém do campo e que partilhou fatos e problemáticas do séc. XX com Michel Foucault e que se debruça sobre esse itinerário foucaultiano por meio de uma homenagem representada por esses últimos Cursos deleuzianos em Saint Denis.

A organização das ideias sobre esses Cursos de Deleuze, neste momento, restringe-se ao Curso de 1985-1986, mais detidamente aos primeiro e segundo encontros (séances). Desse exercício de escuta de Deleuze, emergem alguns elementos como - a forma de oferta e o modo discursivo, a abordagem histórico-crítica e o corpo conceitual que articula o sistema foucaultiano e, principalmente, a leitura e a reflexão de Deleuze acerca desse percurso e dessas construções teórico-metodológico-filosóficas. Nesse percurso, tem-se um outro Foucault revelado por meio da narrativa de um de seus contemporâneos, um filósofo com outras influências, mas com um rigor crítico profundo.

\section{Les cours}

Gilles Deleuze ensina na Université de Vincennes Saint Denis até 1987. Sua docência é iniciada ainda em 1947, nos Liceus de Amiens, de Orleans e de Paris (Louis-Le Grand) e tem sequência, na Educação Superior francesa, entre 1957 e 1960 na própria Sorbonne e entre 1964 e 1969 na Université de Lyon. Desde 1969 e até 1987 (ano letivo 1986-1987), ensina na Université de Paris 8 - Vincennes Saint-Denis, onde há um auditório, hoje, com o seu nome. É possível vê-lo em ações filosóficas, além de ouvi-lo nos Cursos de 1985-1986. Nessas imagens, ele sempre está rodeado de ouvintes e de alunos ${ }^{7}$.

Michel Foucault ensina no Collège de France de 02. dez. 1970, data de sua aula inaugural sobre "A Ordem do Discurso" até 25. jun. 1984, dia em que as complicações decorrentes da SIDA interrompem sua trajetória. Nesse magistério, que teve como último encontro com seu público a aula de 28. mar. 1984, os treze anos e meio foram cindidos em dois grandes blocos. De 1971 a 1976 e de 1978 a 1984. Os cursos desse segundo período conformam um conjunto que parte da direção de consciências da ascese cristã à parresía grega. É certo que em tal período, os cursos do Collège de France ocuparam os primeiros três meses de cada ano. Nos demais, Foucault ensinava em outras partes do mundo, como o Curso de Louvain de 1981 na Faculdade de Direito da Universidade que leva o nome dessa cidade belga, mas também nos Estados Unidos e no Canadá. As viagens ao Brasil, infelizmente, cessaram no primeiro período mencionado. Contudo, é possível colher desse conjunto de encontros com um público flutuante, mas cada vez mais numeroso, elementos que podem ser contrapostos às sessões promovidas por Giles Deleuze, a partir de out. 1985, por meio de Cursos da Université Paris 8, Vicennes Saint Denis.

É muito curioso e fruto do contexto dessas épocas, tanto a limitação dos recursos de registro dessas aulas, assim como os detalhes que emergem dos diálogos de bastidores que

\footnotetext{
${ }^{7}$ A relação completa dos Cursos de Deleuze pode ser visualizada em: https://www.webdeleuze.com/sommaire (Acesso em: 1. maio 2020). Os Cursos sobre Foucault ocorreram entre 22. out. a 17. dez. 1985, por meio de oito sessões sobre "As Formações Históricas" e entre 07. jan. e 03. jun. 1986, por meio de dezoito sessões sobre "O Poder". Seu último Curso acontecerá, justamente, no ano letivo iniciado em 28. out. 1986 e concluído em 02. jun. 1987, sobre Leibniz, primeiro sobre o Barroco e, após, sobre os Princípios e a Liberdade.
} 
precedem e sucedem, além de atravessar continuamente o objeto próprio das reflexões de cada aula. É possível, a partir deles, efetuar um exercício de reconstrução do magistério de um e de outro, bem como compreender um pouco a organização de uma classe regular francesa, em uma instituição tradicional do meio acadêmico, mas permeada de elementos próprios da natureza desses filósofos contemporâneos. É comum verificar, nos registros dos movimentos de maio de 1968, fotografias que reúnem Deleuze e Foucault em diálogo e apoio contínuos aos estudantes. Tais imagens, ao lado de biografias e outros textos, dão conta de uma compreensão diferenciada do papel do intelectual, de um envolvimento forte com as questões de seu tempo e de um diálogo permanente com os seus contemporâneos que excedem as sessões dos Cursos.

Tais elementos permitem observar que o Prof. Deleuze, assim como o Prof. Foucault, tinha liberdade ampla em instituições mais que centenárias, tradicionalíssimas, de um país da Europa Ocidental como a França do final do século XX. Essa liberdade os permitia definir o horário de início, a dinâmica e os momentos que organizavam tais sessões de diálogo e de reflexão com um público silencioso na maior parte do tempo. As aulas eram, pois, reflexões organizadas a partir de elementos estruturantes e que, por vezes, eram acompanhadas de manuscritos ou de textos datilografados (é o caso de Michel Foucault, cujos roteiros datilografados podem ser consultados na Abbaye d'Ardenne).

Deleuze começa com uma certa organização dos tempos. Às 9 horas, inicia com um resgate do encontro anterior. Assinalará, nessa recuperação, as principais ideias que possibilitam retomar seu discurso, fundar sua reflexão e seu pensamento em um movimento que envolve, cadenciadamente, seus ouvintes. Às 9 horas e quarenta e cinco minutos, avança em nova problemática ou dá sequência ao raciocínio que encerrou o encontro anterior para prosseguir em seu curso. Seu estilo é menos vigoroso e ágil que o de Foucault, mas seu francês é bem claro e um ouvido habituado aos Cursos de Foucault se beneficia dessa cadência e de suas pausas generosas. Ele profere um discurso maiêutico. Expõe, pergunta, responde, pondera, explica, retoma, destaca um conceito, prossegue articulando os fios da trama foucaultiana com uma paciência intrigante.

Um último detalhe técnico, as gravações têm menos interrupções e menos perdas em relação às realizadas nos Cursos de Foucault. Não há informações acerca de uma iniciativa institucional nesse sentido, mas é bom recordar que esses Cursos focaultianos foram gravados pelos próprios ouvintes, enquanto a qualidade e a integridade das gravações de Deleuze, poucos anos após, são de qualidade técnica muito superior.

\section{L'approche}

Deleuze faz uma observação curiosa na aula inicial de 22. out., na forma de um apelo aos seus ouvintes. Ele diz, logo após o sobrevoo bibliográfico acerca de Foucault: "faire confiance à l'auteur que vous étudiez". Trata-se de um esforço de escuta, de compreensão, de construção de sentido que é preciso realizar para, segundo Deleuze, "silenciar as vozes da objeção". É preciso e precioso, segundo Deleuze, um esforço de confiança inicial no autor, "deixá-lo falar" e efetuar uma "espécie de análise de frequência" para identificar expressões, assinalar conceitos. Esse esforço inclui perceber a articulação dessas expressões, o entrelaçar de sentidos e de intenções, e ser sensível ao seu estilo. Afirma: "seja sensível às obsessões dele". Certamente, essas advertências iniciais fazem todo sentido para o esforço de compreensão de um autor obcecado e insaciável como Michel Foucault.

Nisso, Deleuze tem extrema razão e sensibilidade ao requerer de seus ouvintes uma benevolência inicial necessária para compreender a frequência de algumas palavras e conceitos em Foucault, expressões-chave no sistema de pensamento desse autor, seus deslocamentos e 
suas recriações de sentido a partir de palavras aparentemente conhecidas, mas que ele preenche e articula em direções cambiantes.

É bom, a esta altura, recordar que a cadeira ocupada por Michel Foucault no Collège de France como ementa inafastável de suas preocupações filosóficas, metodológicas e expositivas dizia respeito a uma "História dos Sistemas de Pensamento" - a saber: como uma problemática se constitui em determinado contexto e se transforma em uma questão filosófica, uma questão da atualidade, que precisa ser enfrentada pelos intelectuais. Trata-se de uma questão invariavelmente vinculada ao presente, mas que não por isso prescinde da História para se constituir. É dessa forma, que questões aparentemente marginais assumem centralidade em seu pensamento: a loucura, o encarceramento, o controle sobre as práticas sexuais, a forma como as relações são estabelecidas entre o sujeito e os outros.

Deleuze tem o cuidado e a sensibilidade de apresentar um Foucault integral, realçado em seus traços hipercríticos, em seu rigor metodológico e em sua busca contínua e inquieta de uma atitude filosófica inquisitiva, erudita e cativante.

Dessa forma, após um sobrevoo inicial acerca das principais obras de Foucault - História da Loucura (1961), Raymond Roussel (1963), Nascimento da Clínica (1963), As Palavras e as Coisas (1966), A Arqueologia do Saber (1969), A Ordem do Discurso (1971), Genealogia da História em Nietzsche (1971), Magritte (1973), Vigiar e Punir (1975) e seu projeto final sobre a História da Sexualidade, por meio da Vontade de Saber (1976) e de Uso dos Prazeres ${ }^{8}$ e do Cuidado de Si (1984), publicados dias antes de seu falecimento. Deleuze é cuidadoso ao enfrentar o problema principal de cada obra e a forma como Foucault o enfrenta de modo a reconstituir como tal questão se transformou assumiu importância em determinado contexto e com tais e quais preocupações.

Após esse sobrevoo e o apelo mencionado, Deleuze retoma para iniciar seu discurso maiêutico de cerca de uma hora e trinta ou quarenta minutos a fim de destacar os conceitos e a forma como Foucault os articula em suas obras.

\section{Le corps conceptuales}

Deleuze constrói uma narrativa muito original e inquietante acerca das obras de Foucault ao passo que articula os eixos e os elementos que revelam as Formações Históricas que deram origem ao hospital, à prisão, ao jogo de luzes e de sombras que se relacionam, na trama deleuziana, aos outros textos contemporâneos de Foucault, aparentemente inusitados, mas que dizem respeito à Arte e, de modo especial, à pintura e às visibilidades. Assim, a História da Loucura $^{9}$, o Nascimento da Clínica e o Vigiar e Punir são mobilizadas em seus eixos, em seus elementos centrais problematizadores de arquiteturas prenhes de visibilidades, em contraposição com a luminosidade inerente à arte de Velásquez (As Palavras e as Coisas), Magritte (Isso não é um cachimbo) e de Raymond Roussel (poesia).

Esse entrelaçar deleuziano a partir da trama foucaultiana ao modo de um itinerário que articula conceitos, aproxima movimentos e faz convergir elementos da formação histórica, como o arquivo e o proceder arqueológico em uma trama que une textos aparentemente distantes em torno de um conjunto de problemáticas, de evidências, de enunciados, de indagações filosóficas ainda contemporâneas em que pese o intervalo de aproximadamente quinze anos entre o primeiro e o último desses textos. Deleuze resgata a trama e faz visível uma espécie de fio condutor que une os livros, prefácios, artigos de Michel Foucault.

A exemplo do entrelaçar de suas vidas, Deleuze dá sentido ao percurso foucaultiano por meio do que denomina de eixos ou focos de interesse que conduzem o pensamento desse filósofo

\footnotetext{
${ }^{8}$ História da Sexualidade II - O Uso dos Prazeres (FOUCAULT, 1984).

${ }^{9}$ Folie et Desraison. Histoire de la Folie à l'Âge Classique. (FOUCAULT, 1961).
} 
contemporâneo, que identificam questões e problematizações. Entre ilustrações e citações, Deleuze enuncia algo muito especial - a incompletude da obra foucaultiana - sobretudo da sequência da História da Sexualidade, por meio do volume inconcluso sobre os Pais da Igreja, que seria lançado em fev. 2018, em Paris, como volume último e integrado por comentários de Frédéric Gros (último editor dos Cursos do Collège de France), ao modo de um Curso inacabado ${ }^{10}$.

Os enunciados assumem uma centralidade sem igual na narrativa deleuziana sobre Foucault, em vista de trazerem à luz, à visibilidade, as questões de cada época, as condições que expressam um trabalho de elaboração filosófica em vez de histórica. Esses enunciados conformam a própria condição que possibilita comportamentos e mentalidades (DELEUZE, 1985). Tal é a conclusão de Deleuze após incluir em sua análise a Arqueologia do Saber (1969).

Assim, conclui Deleuze: "Voir et parler déterminent des conditions dans la mesure où voir se dépasse vers les champs de visibilités et parler se dépasse vers les régimes d'énoncés" (DELEUZE, 1985). Nesse contexto, a arqueologia foucaultiana equivale à análise das formações históricas.

\section{Quelques mots pour conclure}

Este conjunto de reflexões a partir do exercício de ouvir Deleuze sobre Foucault foi apresentado, em versão preliminar, no Encontro realizado no início de novembro de 2019, na Faculdade de Educação da Unicamp, em três riquíssimos encontros como programação em três períodos e que ainda contou com um quarto especial acerca de trabalhos do campo da Educação Matemática, em especial, de sua vertente Etnográfica, Etnomatemática. A discussão foi proposta em uma mesa que trazia outros trabalhos sobre o pensamento de Deleuze e de Foucault e, apesar de serem pesquisadores conhecidos dos presentes e ouvidos em outras oportunidades, foi extraordinária a forma como se apresentaram no sentido de suas percepções acerca do exercício da escuta, do exercício da leitura e desse articular conceitual e filosófico que, cada qual, procura se apropriar e, fundamentalmente, mobilizá-los no campo da Educação.

A partir da preocupação ética do "Último Foucault" (1978-1984), com as práticas de si em especial, com a escrita de si, a escuta de si, as epístolas e outras notas que possibilitaram, entre os gregos antigos, um trabalho de si sobre si, que passa pelo souci de soi, mas que, em Foucault, assume a forma de um verdadeiro caleidoscópio. Esse objeto gira diante dos leitores, dos ouvintes dos Cursos gravados e das releituras realizadas por tantos investigadores que o fazem iluminar problemáticas da Educação, do Ensino, das relações entre sujeitos e seus outros.

A sensibilidade deleuziana na narrativa sobre Foucault possibilitou um exercício de releitura, de uma nova compreensão, que partiu da "confiança no autor", não apenas em Foucault, mas também naquele que se apropria dessa trajetória intelectual e filosófica para recontá-la, ao modo de uma homenagem especialíssima e o tomando como um pensador contemporâneo imprescindível para a compreensão desse final de século XX, de um mundo ainda imerso na Guerra Fria, e anterior à queda da URSS, da Reunificação Alemã, da emergência dos grandes blocos econômicos que dariam origem, bem mais tarde, a uma Europa unificada em uma Comunidade, e, agora, com questões de outra ordem.

\footnotetext{
${ }^{10}$ A proximidade desse texto (FOUCAULT, 2018) se dá com o Curso de 1981, Subjetividade e Verdade, e não com o percurso final composto por três cursos proferidos no Collège de France sobre o souci de soi (1982) e sobre a parresía (1983 e 1984). É bom lembrar que essas são as referências sempre do momento exato de realização das aulas, vez que Foucault preferia o período compreendido entre jan.-mar. ou abr. de cada ano, mas que na verdade se referia ao ano letivo iniciado no ano anterior e que seria concluído em jun. do seguinte. Exemplo, o curso de 1982, a Hermenêutica do Sujeito, é na verdade o Curso da temporada 1981-1982, ministrado de fato entre jan. e abr. de 1982, no Collège de France.
} 
Em outubro de 1986 e, portanto, no início de um ano letivo que seria concluído apenas no ano seguinte, Deleuze refaz o percurso intelectual foucaultiano como uma travessia intelectual repleta de desafios e jogos que atravessam a História, a Linguagem, as Ciências Humanas e Sociais em sentido amplo, por meio de uma problematização filosófica inquieta e inquietante, rigorosa e crítica de si, que impulsionou Foucault ao longo de trinta e cinco anos., do final dos anos 1950 até 1984 e que passa por saber, poder e ética. Mais do que uma narrativa especializada do percurso intelectual de um pensador contemporâneo, Deleuze toma Foucault como uma personalidade filosófica, mas também como um seu contemporâneo e com quem compartilhou questões cotidianas fundamentais, além de batalhas políticas como o movimento estudantil de resistência do final dos anos 1960, o movimento em defesa e escuta dos presos, realizado pelo GIP no início dos anos 1970, e a trajetória foucaultiana de treze anos e meio no Collège de France, acompanhada de muito próximo por Deleuze a partir de Saint Denis.

Percebe-se, mais de que um enfrentamento crítico, uma admiração profunda da capacidade de problematização e de reflexão de Michel Foucault (DELEUZE, 1998: 127), observadas as filiações filosóficas distintas (École Normale e Sorbonne), mas que compartilharam um compromisso profundo com o presente, com o acontecimento e com um esforço de compreensão da vida em sociedade e de seus atravessamentos pelo saber, pelo poder e pela forma como os homens conduzem a si mesmos e os outros. Nas palavras iniciais de Deleuze, trata-se de um "pensamento que inventa coordenadas, que se desenvolve ao longo de eixos" (DELEUZE, 1985). São, sobretudo, as evidências foucaultianas que Gilles Deleuze põe em evidência em sua narrativa. Um percurso belíssimo, permeado de ilustrações e de imagens em movimento que resgatam o admirado intelectual ${ }^{11}$ e o investigador contumaz personificados por Foucault.

Em que pese este exercício demandar outros tempos de escuta e de elaboração da narrativa deleuziana acerca da construção que realiza a partir dos eixos, enunciados, sentidos e significados empregados por Foucault em seu itinerário, é possível verificar o potencial de retomada do pensamento de um dos mais intrigantes intelectuais contemporâneos por meio desse convite deleuziano. Dessa forma, é preciso, de fato, "faire confiance à l'auteur que vous étudiez" (DELEUZE, 1985).

Com Chartier (2002), tem-se que a prática de leitura de Deleuze enriquece, a partir de sua singularidade, a compreensão desse autor por meio de uma nova leitura.

Portanto, aprender pela escuta de Deleuze acerca de Foucault não é apenas um desafio de retomar esse autor, mas de compreender também o pensamento por meio das conversações de Gilles Deleuze com seus ouvintes por meio de uma análise filosfófica. Écouter pour comprener.

\section{Les Références}

CHARTIER, Roger. A história cultural: entre práticas e representações. Trad. Maria Manuela Galhardo. 2. ed. Rio de Janeiro: Bertrand Brasil; Lisboa: Difel, 2002.

DELEUZE, Gilles. Sur Foucault: les formations historiques. cours à l'Universitè de Vincennes Paris 8, 22. oct. 1985, séance 1. dur. 2h09'36”. Disponível em: https://www.youtube.com/watch?v=JfmdzQIZpPI e em: https://www.webdeleuze.com/sommaire ou em https://www.webdeleuze.com/textes/264. Acessos em: 12. Out. 2019 e em 1. maio 2020.

DELEUZE, Gilles. Um Retrato de Foucault - entrevista a Claire Parnet, 1986. In: DELEUZE, Gilles. Conversações - 1972-1990. Trad. Peter Pál Pelbart. 2. reimp. São Paulo: Ed. 34, 1998.

\footnotetext{
11 Sobre esse engajamento, ver Noiriel. "Michel Foucault: les trois figures de l'intellectuel engagé” (In: GRANJON, 2005: 301-330).
} 
FOUCAULT, Michel. Les aveux de la chair: histoire de la sexualité, iv. Éditions de Frederic Gros. Paris: NRF/Gallimard, 2018.

FOUCAULT, Michel. L'usage des plaisirs: histoire de la sexualité, II. Paris: Gallimard, 1984.

FOUCAULT, Michel. Dits et écrits. Paris: Quarto/Gallimard, 2017 [Bibliothèques des Sciences Humaines].

FOUCAULT, Michel. Surveiller et punir. Paris: Gallimard, 1975 [Bibliothèques des Histoires].

FOUCAULT, Michel. Preface. In: FOUCAULT, Michel. Folie et desraison. histoire de la folie à l'âge classique. Paris: Plon, 1961, p. I-XI. Disponível em: http://1libertaire.free.fr/MFoucault155.html. Acesso em: 13 out. 2019.

GRANJON, Marie-Christine. Bibliographie Chronologique des ouvrages de Michel Foucault. In: Penser avec Michel Foucault. theorie critique et pratique politique. Paris: Éditions Karthala, 2005, p. 337-40 [Recherches Internationales]. Disponível em: https://www.cairn.info/penseravec-michel-foucault--9782845866072.htm. Acesso em: 12 out 2019. 